those which we have shown normally carry a disproportionately large part of the blood flow, the loss of gas exchange per unit of ventilation in the apex of the lobule will be particularly marked. Compared with the normal the apical lobular space in centrilobular emphysema will be particularly "dead." A significant part of the very large physiological dead space often seen in emphysema may be accounted for in this way.

\section{Pulmonary Embolism}

Pulmonary embolism is another condition in which increases in pulmonary vascular resistance may appear to be far greater than would be expected from the degree of anatomical vascular obstruction. In experimental pulmonary microembolism, too, the injection of relatively small quantities of tiny particles produces a marked rise in pulmonary vascular resistance. Widespread pulmonary vasoconstriction has been invoked to explain both phenomena, but one would suggest that considerations similar to those of the last section may, at least in part, explain the features observed.

The technique used by Wagner et al. (1967) to explore the lobular distribution of blood flow in the rat involved intravenous injection of radioactive particles of a size designed to impact predominantly in pulmonary capillaries. Subsequent counting of these particles showed a gradient of concentration (and hence of blood flow), with the greatest concentration in the central segments of the lobule. If, then, particulate matter of the same general size reaches the lungs via the blood stream, one would expect it to become impacted preferentially in the more central portions of the lobules. The results will be similar to those shown by the "central" line in Fig. 3. Embolization by sufficient particulate matter to produce widespread obstruction of vessels in the proximal $30 \%$ of each lobule would lead to a doubling of pulmonary vascular resistance, and obstruction of the vessels in the proximal $50 \%$ of lobules to more than a trebling of pulmonary vascular resistance. Relatively small amounts of particulate embolic material might thus produce large increases of pulmonary vascular resistance.

In addition, preferential reduction of blood flow in the proximal part of the lobule (where ventilation is greatest) would once more contribute to the very large physiological dead space which is a feature of clinically severe pulmonary embolism.

It is not certain whether microembolism plays a significant part in the overall picture of pulmonary embolism in man. If it does in fact occur, the present considerations suggest that it may make a major contribution to the clinical and haemodynamic features.

The original work referred to from this department was supported by grants from the National Heart Foundation of Australia, the Australian Research Grants Committee, and the Medical Research Fund of the University of Sydney.

\section{REFERENCES}

Cumming, G., Crank, J., Horsfield, K., and Parker, I. (1966). Respiration Physiology, $1,58$.

Cumming, G., Horsfield, K., Jones, J. G., and Muir, D. C. F. (1968). In Form and Function in the Human Lung, edited by G. Cumming and L. B. Hunt, p. 56. Livingstone, London.

Horsfield, K. (1968). In Form and Function in the Human Lung, edited by G. Cumming and L. B. Hunt, p. 242. Livingstone, London.

Read, J. (1966a). Fournal of Applied Physiology, 21, 1511.

Read, J. (1966b). Fournal of Applied Physiology, 21, 1521.

Wagner, P., McRae, J., and Read, J. (1967). Fournal of Applied Physiology, 22, 1115 .

\title{
COMPUTERS IN MEDICINE
}

\section{Locating the Elderly in a General Practice*}

\author{
J. A. FORBES, $\dagger$ M.A., M.D.
}

\begin{abstract}
Cummary : A preliminary survey undertaken before $\checkmark$ compiling a geriatric register showed that about $90 \%$ of the information on the practice files for patients over 65 was accurate. It is emphasized that such a registerwhich should be as accurate and up-to-date as possibleis important for the successful organization of a preventive geriatric clinic, or to any project designed to "screen" a defined population.
\end{abstract}

In the National Health Service we have opted for the universalist approach, where medical care is available to all who require it. Nevertheless, one of the disadvantages of this method is that the available facilities may not be fully utilized. Certain groups in the population know how to make effective and frequent use of a service, while others for a variety of reasons do not. The universalist method may therefore fail or not realize its full potential if certain groups do not use the services available, and a more categorical approach becomes necessary aimed at bringing the service to the patient, or at least taking steps to ensure that the services are widely known.

It would appear that the elderly form one of these groups. Some old people are too apathetic, or too humble, or are

* From the Oxford Record Linkage Study, Headington, Oxford. † General Practitioner, Bicester, Oxford. incapable of communicating effectively, while a small minority, often the most vocal and militant, receive more care than they merit. The result is an unbalanced service, with the available resources concentrated on the few to the detriment of the remainder. It would seem, therefore, that the logical approach is to try to bring the service to the patient by making an assessment of the medical and social needs of all patients in a given category and deploying the existing resources according to these needs.

With this in mind it was decided in this practice to start a preventive geriatric clinic, where all patients over the age of 65 registered with the practice would have a social assessment by the health visitor, followed where necessary by a physical examination by one of the partners in the practice. As an essential first step it was necessary to compile a geriatric register consisting of the names, addresses, and ages of all patients over 65 in the practice and to ensure so far as possible that this information was accurate. This paper describes the method used, by sampling techniques, to determine whether our information about the existence and whereabouts of the elderly in the practice was sufficiently accurate for our needs.

\section{Material and Method}

The practice described is situated in North Oxfordshire. There are three partners, and the practice is associated with the 
Oxford Record Linkage Study (Acheson and Forbes, 1968). The following information about every patient registered with the practice on 1 July 1966 and those joining thereafter has been recorded on 80-column punch-cards.

Card 1.-Identification Data, including names, N.H.S. number, and date of birth.

Card 2.-Statistical Data, including age, sex, geographical zone in the practice, distance from central surgery, dispensing or nondispensing patient, and date of registration.

Card 3.-Full postal address.

The three cards are linked by means of a unique serial number (not the N.H.S. number). Additional cards are punched for modification of information including changes of address and for deletions from the list by either death or withdrawal. This is done on a weekly basis. So far processing has been done by business machines under the aegis of the Oxford Record Linkage Study. In future as more data is added about each patient a computer will be used.

It was felt that with such facilities at our disposal we were in a strong position to compile an accurate up-to-date geriatric register. A list was made of all patients who had reached the age of 65 on or before a specified date, including full name, address, sex, and date of birth. The list was divided into four groups.

Group A.-This group consisted of a number of Central Europeans employed at a local Army depot. Since they all had the same address, and since it was felt that the response rate to a circular letter by this group would be low, the camp leader was asked to check the list for accuracy.

Group B.-This group consisted of the residents of a local authority welfare home. The list was checked by the matron of the home.

Group C.-In this group there were several patients who had made no contact with the practice for some years, and it was felt that some of these patients might have died. To avoid causing distress to relatives inquiries were made indirectly-for example, from the electoral roll, from neighbours, and by members of the staff visiting the patients' homes.

Group D.-For the remaining patients the procedure was as follows. When two patients lived at the same address one name, usually that of the wife, was deleted and from the remaining names a one-in-two sample was taken. A letter was sent to each of these patients explaining the object of the inquiry, and they were asked to reply within seven days if the name and address stated were correct. If no reply was received within 14 days it was assumed that the information we had on file was inaccurate. Subsequent investigations proved this assumption to be correct.

\section{Results}

There were 522 patients $(7 \cdot 6 \%)$ over the age of 65 in the practice. The results from the four groups are shown in the Table, which shows that about $90 \%$ of the information we had on file was accurate and up to date.

Proportion of Accurate Addresses in Each Group

\begin{tabular}{c|c|c|c|c}
\hline Group & $\begin{array}{c}\text { No. of } \\
\text { Records }\end{array}$ & $\begin{array}{c}\text { No. with } \\
\text { Correct Address }\end{array}$ & $\begin{array}{c}\text { No. with } \\
\text { Incorrect Address }\end{array}$ & $\begin{array}{c}\% \text { of Accurate } \\
\text { Addresses }\end{array}$ \\
\hline A & 56 & 41 & 15 & $\begin{array}{r}73 \cdot 2 \% \\
\text { B }\end{array}$ \\
C & 18 & 26 & 6 & $100.0 \%$ \\
D & 164 & 153 & 11 & $96.6 \%$ \\
\hline Total & 264 & 232 & $32 * 3 \%$ \\
\hline
\end{tabular}

* This figure includes 4 cases $(1.5 \%)$ in which the patients had died without the * This figure includes 4 cases $(1$
fact being racorded in the notes.

\section{Discussion}

No one who has made a study of the community services available to the elderly can fail to be impressed by their range and content, and yet they tend to be fragmented, poorly publicized, and lacking in unified control. Most general practi- tioners will have experienced the frustration of trying to mobilize community resources quickly, efficiently, and economically. If these efforts fail it often means the transfer of an elderly patient to hospital or residential home, not because of insurmountable social problems, nor because of difficulties in diagnosis or treatment, but because the patient's needs cannot be satisfied quickly enough. It is hoped that by instituting a preventive geriatric clinic such situations may be prevented or postponed-or at least to some extent foreseen-so that calm and rational, rather than hurried and expedient, decisions may be made when a patient faces social and medical breakdown.

Such a scheme would appear to be feasible in general practice, but it has little prospect of genuine success unless the elderly can be identified and their whereabouts determined with accuracy. No amount of funds or staffing will make such a scheme work unless adequate coverage is assured, because experience would suggest that the minority who are not identified, and whose whereabouts are unknown, are likely to be those most in need of help.

This is a fundamental point if preventive medicine techniques are to be used effectively in general practice. If, for example, it were considered desirable in a practice to identify all female patients in a specified age group for the purpose of cytological examination of the cervix, it would be necessary as a first step to compile a list of all women between the ages of, say, 35 and 60. This presupposes the existence of an age-and-sex register which has been continually kept up-to-date, and an accurate record of the patients' whereabouts. Moreover, a system must be devised whereby all women as they reach the age of 35 , and those who join the practice between the ages of 35 and 60, are added to the list while those in the same age group who leave the practice, die, or reach the age of 61 are deleted from the list.

This practice's association with the Oxford Record Linkage Study, and its access to Oxford Regional Hospital Board data processing facilities, make any project which includes the identification of individual patients or groups of patients a practical proposition. It should, however, be possible to offer the same service to all practices in an executive council area. Indeed, it is the declared policy of the Ministry of Health that executive councils should where possible provide individual practices with current lists of patients over the age of 65 , but while executive councils continue to employ manual clerical systems the possibility of providing this service on a wide scale must remain remote.

The idea of setting up geriatric registers is not new. Many local authorities have initiated schemes, but few have put them into practice. The first questions to be posed remain the same whether such plans are organized by local authorities or by the general-practitioner services: "Who should be on the register ?" "Where do they live ?" "Is the register complete and up-to-date?" "Is there a simple means of keeping the register up-to-date in the future ?" Though our results show that the information we had on file was only $90 \%$ correct, we regard this as sufficient to justify the methods employed and adequate as the basis for the operation of a register.

In the future it is hoped that this project of creating a file of important social and medical data for a defined population using punch-cards and business machines will be extended to other practices in the executive council area. Should this prove feasible a computer will be used, and it would then be possible to have a computer-held register of all elderly patients in the community.

This investigation has been made possible by the use of funds allocated by the Nuffield Provincial Hospitals Trust to the Oxford Record Linkage Study.

\section{REFERENCE}

Acheson, E. D., and Forbes, J. A. (1968). British fournal of Preventive and Social Medicine, 22, 105. 